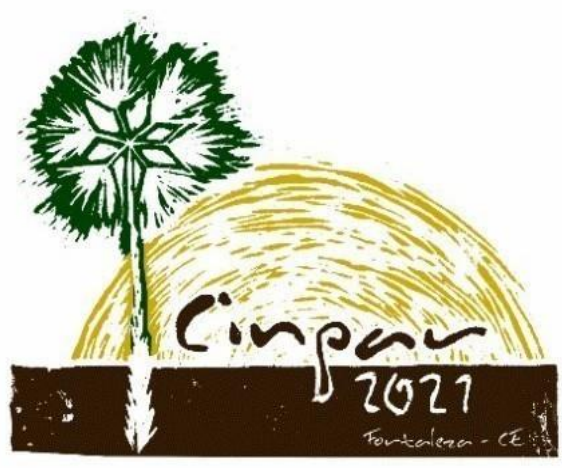

XVII Congresso Internacional sobre Patologia e

Reabilitação das Construções

XVII Congreso Internacional sobre Patología y Rehabilitación de las Construcciones

XVII International Conference on Pathology and Constructions Rehabilitation

FORTALEZA (Brasil), 3 a 5 de junho de 2021

https://doi.org/10.4322/CINPAR.2021.118

\title{
Investigação das manifestações patológicas nas fachadas do prédio do setor ambulatorial do Hospital das Clínicas-UFPE
}

\section{Investigations of pathological manifestations on the facade of the ambulatory sector building at the Hospital das Clínicas-UFPE}

\author{
Leonardo Lima Carvalho ${ }^{1}$, Adegilson José Bento ${ }^{2}$, Eliana Cristina Barreto Monteiro ${ }^{3}$ \\ ${ }^{1}$ Universidade de Pernambuco - Escola Politécnica de Pernambuco, Recife, Brasil, leonardolc94@hotmail.com \\ ${ }^{2}$ Universidade de Pernambuco - Escola Politécnica de Pernambuco, Recife, Brasil, ajb_pec@poli.br \\ ${ }^{3}$ Universidade de Pernambuco - Escola Politécnica de Pernambuco, Universidade Católica de Pernambuco, \\ Recife, Brasil, eliana@poli.br
}

\begin{abstract}
Resumo: O prédio principal do Hospital das Clínicas é uma edificação com 41 anos de idade (EBSERH, 2020), e que naturalmente através da ação do tempo, da natureza e de seu uso, ocasionaram em diversos aspectos de suas instalações o surgimento de manifestações patológicas. Este trabalho teve o intuito de identificar e avaliar os problemas presentes nas fachadas do prédio em que funciona o setor ambulatorial, assim como nos seus elementos componentes como brises, cobertas entre outros. Como metodologia foram adotadas as seguintes etapas: levantamento histórico e de informações pertinentes sobre o edifício, inspeção visual e registro fotográfico. Como resultado do trabalho, foram identificadas diversas manifestações patológicas, tais como: corrosão de peças metálicas; desplacamento e fissuração do concreto; mofo, bolor e lodo nos revestimentos cerâmicos e de pintura. Para a maioria dos problemas, seu surgimento se relaciona à ação do tempo, estando sujeitas a agressividade do meio, porém, muitos desses problemas seriam evitados com uma rotina de inspeção e manutenções em idades iniciais.
\end{abstract}

Palavras-chave: Inspeção. Fachadas. Hospital.

Abstract: The main building of the Hospital das Clínicas is a edification with 41 years-old (EBSERH, 2020), and naturaly through the action of time, enviroment and of your use, occasioned in different aspects of your installations pathological manifestations. This work aims to identify and evaluate the problems present on the facade of the building where the ambulatory sector works, as well as in its component elements such as brises and roofing among others. As a methodology, the following steps will be taken: search for relevant information about the building, historical survey, analisis and photographic register. As a result of the work, several pathological manifestations were identified, such as: corrosion of metallic parts, cracking and detachment of concrete and mold, and sludge in ceramic and paint coatings. For most problems, its appearance is related to the action of time, being subject to the aggressiveness of the environment, however, many of these problems would be avoided with a routine of inspection and maintenance at early ages 


\section{Introdução}

A área de Patologia das Edificações é um campo da Engenharia Civil que se faz bastante importante para qualquer tipo de construção, com ela é possível sanar problemas de maneira mais eficaz e segura. É indispensável a qualquer construção que haja manutenção de suas partes, para tal, é necessário rotinas de inspeção executadas por profissionais habilitados.

$\mathrm{Na}$ cidade do Recife o meio é bastante agressivo para as estruturas de concreto armado, fazendo necessária investigações e manutenções de problemas existentes. O prédio do Hospital das Clínicas foi escolhido para se demonstrar a importância de se realizar uma investigação de manifestações patológicas em unidades de saúde, pois como foi apresentado por Lima (2018), no prédio do Hospital do Câncer o atendimento de um dos consultórios estava suspenso por conta do grau de deterioração da laje de concreto.

O trabalho teve o intuito de coletar dados sobre a situação atual do hospital, através da inspeção ao edifício e realizando um registro fotográfico. Através do estudo, foi possível compilar e detalhar informações importantes sobre as manifestações encontradas, para que os profissionais da área consigam intervir de maneira eficaz e segura.

\section{Caracterização}

O Hospital das Clínicas localizado no campus da Universidade Federal de Pernambuco no Recife é uma construção com 41 anos de idade (EBSERH, 2020). Na Figura 1 pode-se observar por uma vista aérea a localização do prédio principal do hospital, mostrando o formato de " $\mathrm{H}$ " da edificação, no total com uma área construída de 64 mil metros quadrados, onde funcionam centros cirúrgicos, UTI's, maternidade e ambulatórios das mais variadas especialidades. No setor ambulatorial do hospital são atendidas 5600 pessoas por mês em média (EBSERH, 2020), desta forma um prédio que presta um serviço tão importante para a população pernambucana não pode ter sua atividade prejudicada.

A região da cidade do Recife apresenta um ambiente bastante agressivo para as edificações, assim como indicado na NBR 6118 (ABNT, 2014), onde é classificado como classe III de agressividade ambiental, o que representa grande risco de deterioração para a estrutura.

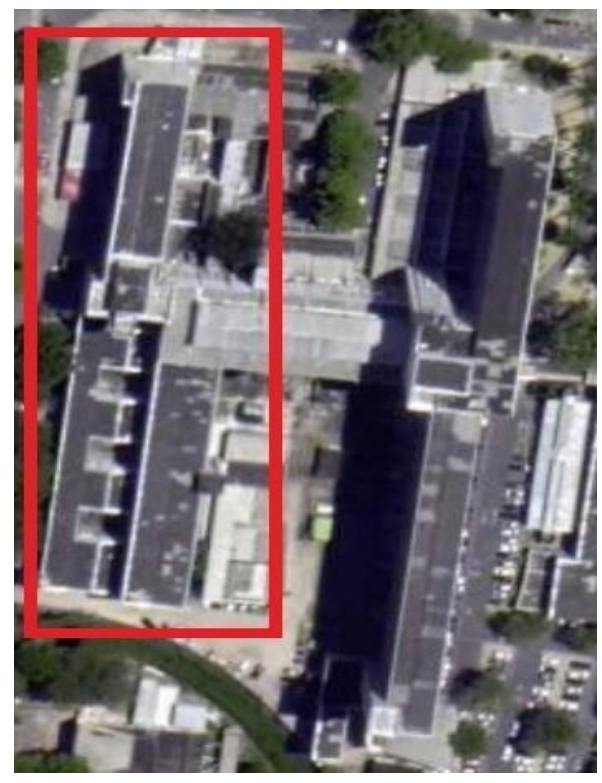

Figura 1 - Vista áerea do Hospital das Clínicas

Sua arquitetura se destaca pelo uso de brises externas e internas, e tem a presença de 2 tipos de revestimentos em sua fachada, pintura e cerâmica. Dois quadros foram elaborados para descrever características das fachadas inspecionadas. No Quadro 1 são apresentadas as fachadas leste e oeste. 
Quadro 1 - Características das fachadas leste e oeste.

\begin{tabular}{|c|c|}
\hline Fachada oeste \\
\hline Acesso à maternidade
\end{tabular} \mid \begin{tabular}{c} 
Acesso área de manutenção e estacionamento \\
\hline Extensão: 30 metros
\end{tabular}

No Quadro 2 a fachada principal foi separada em dois segmentos, pois suas características físicas variam bastante. 0 10 segmento da fachada com 5 andares, tem sua fachada praticamente formada por brises, além de dois pequenos trechos revestidos de cerâmica e pintura. 02 을 segmento da fachada também em sua maioria é composta por brises, tendo no total 4 andares, porém os dois últimos andares são limitados em torno de 7 metros em relação aos dois primeiros, fazendo com que fiquem com pouca visualização para quem está no nível do solo.

Quadro 2 - Característica da fachada principal.

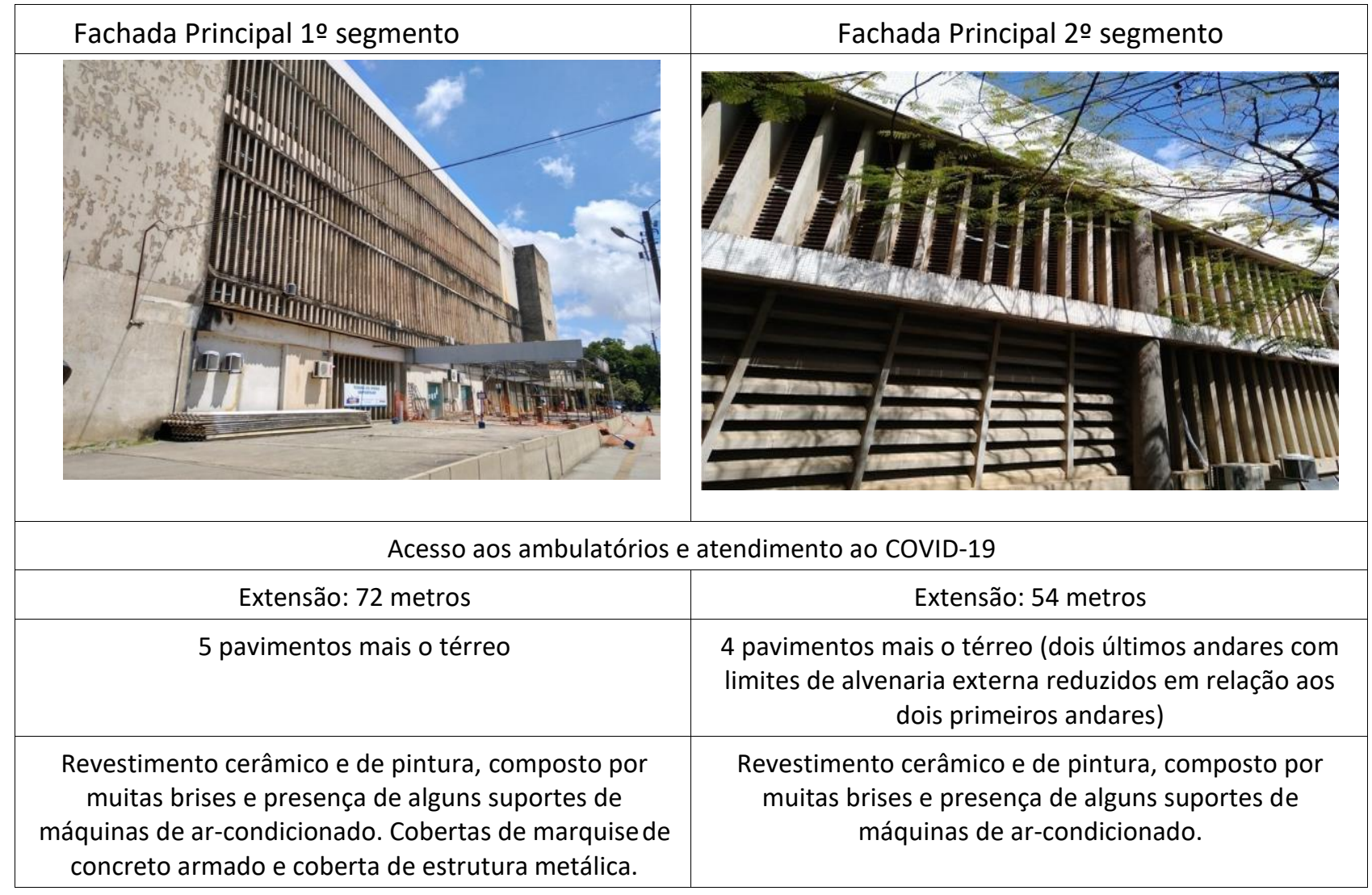




\section{Origens e principais tipos de manifestações patológicas em fachadas}

Uma definição importante para o entendimento deste trabalho é a classificação das manifestações por sua origem segundo a NBR 16747 (ABNT, 2020), resumidamente as manifestações podem ser classificadas em 3 tipos:

- Endógenas ou construtivas: quando a perda de desempenho decorre das etapas de projeto e/ou execução;

- Exógena: quando a perda de desempenho relaciona-se a fatores externos à edificação, provocados por terceiros;

- Funcional: quando a perda de desempenho relaciona-se ao envelhecimento natural e consequente término da vida útil;

As manifestações mais recorrentes em fachadas são:

- Corrosão: de acordo com o Departamento Nacional de Infraestrutura de Transportes - DNIT (2010), a corrosão pode ser originada pela reação química ou eletroquímica das peças metálicas.

- Fissuras/desplacamento (concreto): ainda pela definição do DNIT (2010), o aumento do volume das barras oxidadas geram o aumento de tensões dentro da peça de concreto, provocando fissuras e posteriormente o seu desplacamento.

- Fissuras (alvenaria/cerâmica): Oliveira (2019), definiu alguns tipos de origens para fissuras em alvenarias, foram elas: fissura por concentração de tensões em cantos de janelas; fissura por retração; fissuras de dilatação e contração no encontro da alvenaria com a estrutura, fissuras devido à sobrecarga da laje, fissuras devido à movimentação térmica e fissuras devido à movimentação higroscópica.

- Manchas (sujeira): Para Terra (2001), a poeira pela ação do vento e de forças de adesão, se aderem a superfície do material.

- Bolor/Mofo: Silveira (2019), apresenta a definição de bolor e mofo sendo fases subsequentes da aglomeração de fungos por meio da constante umidade. O bolor é a fase inicial, mais superficial.

- Descascamento (pintura): Dos Santos (2010), relaciona as causas do descascamento de pinturas à falta de um fundo preparador, diluição incorreta da tinta e ação da infiltração de água na pintura.

- Descolamento de cerâmicas: Para Souto (2017), quando as tensões absorvidas no revestimento cerâmico forem maior que a capacidade de aderência das ligações entre as placas e os revestimentos.

- Gretamento: Para Groff (2011), o gretamento ocorre devido às diferenças de capacidade de se absorver deformações encontradas entre a base da placa cerâmica e a camada de esmalte, formando dessa forma a perda e fissura da camada esmaltada. 


\section{Metodologia}

Foi escolhido como objeto de estudo as fachadas do prédio do Hospital das Clínicas onde funcionam principalmente os ambulatórios, setor de atendimento ao COVID-19 e maternidade. As fachadas analisadas foram a principal, que compreende o setor de COVID-19 e os ambulatórios, a fachada oeste que abriga a maternidade e a fachada leste onde funciona um estacionamento e entrada para área de manutenção.

A fachada posterior do hospital não entrou no estudo em razão da dificuldade de acesso e visualização dos seus elementos em detalhes. Na fachada principal, as brises que se encontravam fora do alcance de visão na 2 a parte, só puderam ser observadas adentrado o hospital na área de circulação para os ambulatórios, porém as brises da 1a parte não puderam ser observadas, pois o acesso à esta área é restrito, ainda assim se pôde observar a presença de manchas escuras, possivelmente sujeiras como bolor e lodo.

Para a realização deste trabalho, foram feitas visitas técnicas ao longo dos meses de setembro e outubro de 2020. Nestas visitas foram feitos registros fotográficos e anotações acerca das manifestações encontradas nas fachadas laterais e frontal do setor ambulatorial do HC. Foram utilizadas como material de pesquisa consultas a normas específicas, entre outros autores para fundamentar a classificação e caracterização das manifestações patológicas encontradas.

\section{Resultados e discussões}

A seguir encontram-se os elementos da fachada em quais foram identificadas manifestações patológicas. Algumas dessas manifestações oferecem risco de acidentes, considerando a possibilidade de queda dos elementos deteriorados.

\subsection{Estruturas metálicas e de concreto armado}

A situação da deterioração das brises, da marquise, da estrutura metálica da coberta e dos suportes para máquinas de climatização, se mostram um evidente risco de vida para os usuários e demais pessoas que possam passar próximo à fachada do prédio. Foram identificadas manifestações como corrosão das partes metálicas, fissuras e desplacamento do concreto.

\subsection{1 - Coberta}

Na Figura 2 é apresentada a entrada para o setor de atendimento ao COVID-19 que conta com uma coberta de estrutura metálica que no início das visitas no mês de setembro se encontrava bastantedegradada.

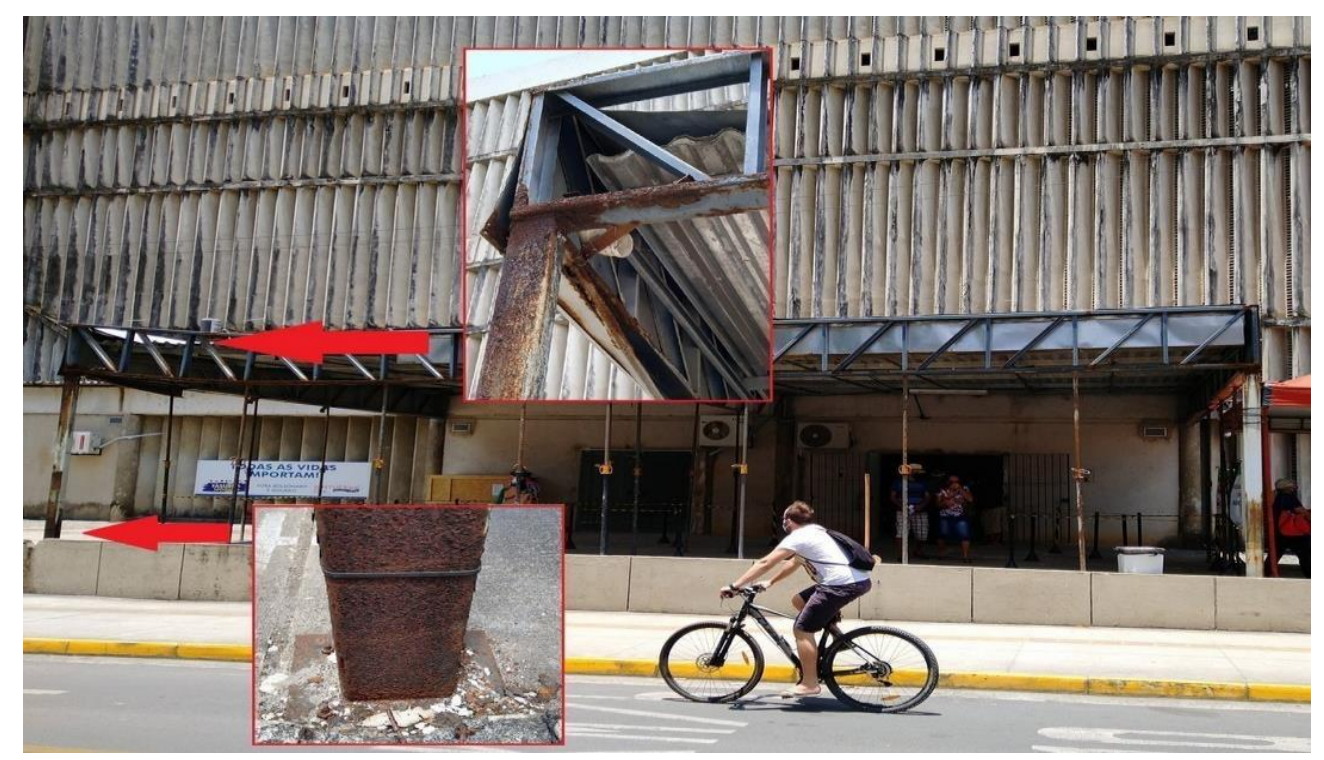

Figura 2 - Coberta metálica e suas manifestações 
Uma das treliças se encontravam com uma deformação bastante acentuada, provocada pelo processo de corrosão das peças metálicas. Haviam também escoras metálicas servindo de apoio à estrutura, mas não pareciam garantir por muito tempo o suporte da estrutura. Existia também o risco das escoras serem deslocadas pela ação de terceiros, já que estavam em local de passagem de pedestres e não havia nenhum tipo de fixação entre as peças e a estrutura.

No fim do mês de outubro em outra inspeção visual ao local, foi observada a interdição da área e o início dos serviços de reestruturação da coberta, apresentados na Figura 3.

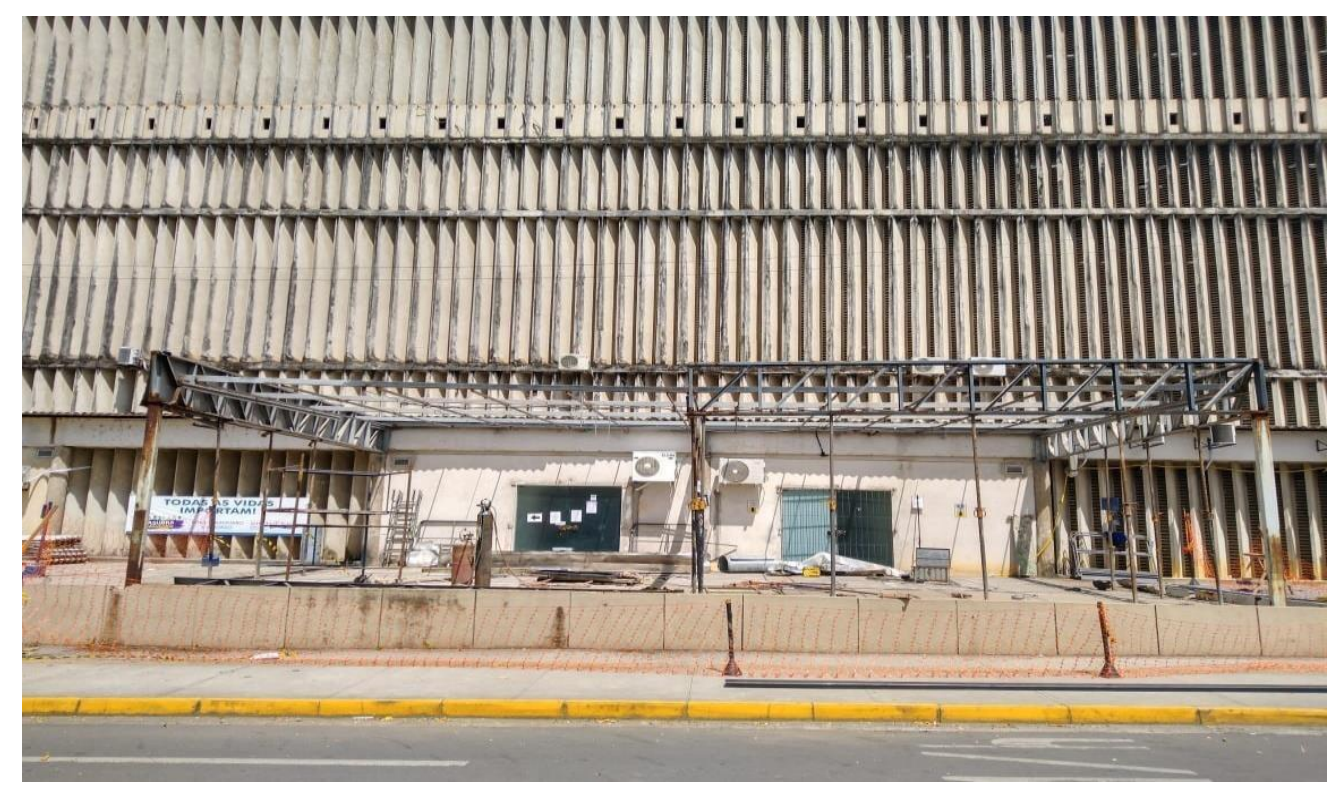

Figura 3 - Reestruturação da coberta metálica

\subsection{2 - Brises}

Este é o elemento da fachada que mais chama atenção, pois compõe praticamente toda a fachada frontal e aparecem também na fachada leste. A deterioração desses elementos representam risco de vida e de dano ao patrimônio, tendo um grande trecho de passagem de pedestre na fachada principal e um estacionamento na fachada leste. Foram identificadas 3 manifestações, e que podem ser consideradas etapas de um mesmo problema: a corrosão das armaduras, o fissuramento do concreto e o desplacamento do concreto. Na Figura 4 ficam identificados as etapas deste processo de deterioração.

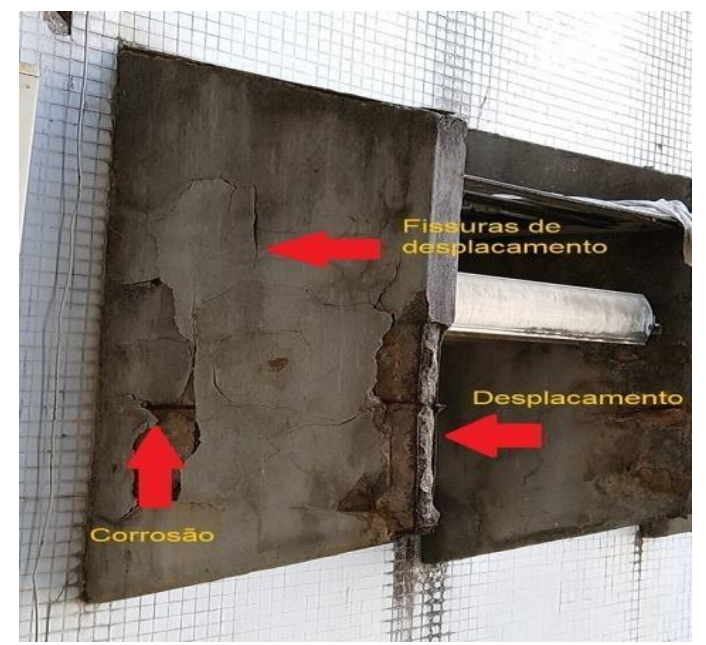

Figura 4 - Evolução das manifestações numa das brises da fachada leste 
Com a expansão da armadura da brise ocasionada pela corrosão, começa também o surgimento de fissuras, que com o passar do tempo se agravam ocasionando o desplacamento do concreto. Apesar de ser uma construção com mais de 40 anos, o seu cobrimento chega muito próximo ao recomendado pela norma atual. Atualmente o indicado pela NBR 6118 (ABNT, 2014) é que se tenha $3 \mathrm{~cm}$ de cobrimento, e na norma vigente na época em que foi construído, que tivesse $2,0 \mathrm{~cm}$, justamente o que foi medido in loco, como mostra a Figura 5. Não se pode afirmar que apenas o cobrimento tenha tido grande impacto para o aparecimento das manifestações, mas também a qualidade do material da época, uma vez que a resistência era o parâmetro mais importante e não a durabilidade. Conclui-se que a ação de degradação das brises ocorreu principalmente de forma natural, estando expostas à agressividade do meio além da falta de manutenção. Se as brises tivessem sido construídas atendendo aos parâmetros recomendados atualmente provavelmente estaria em melhor condições.

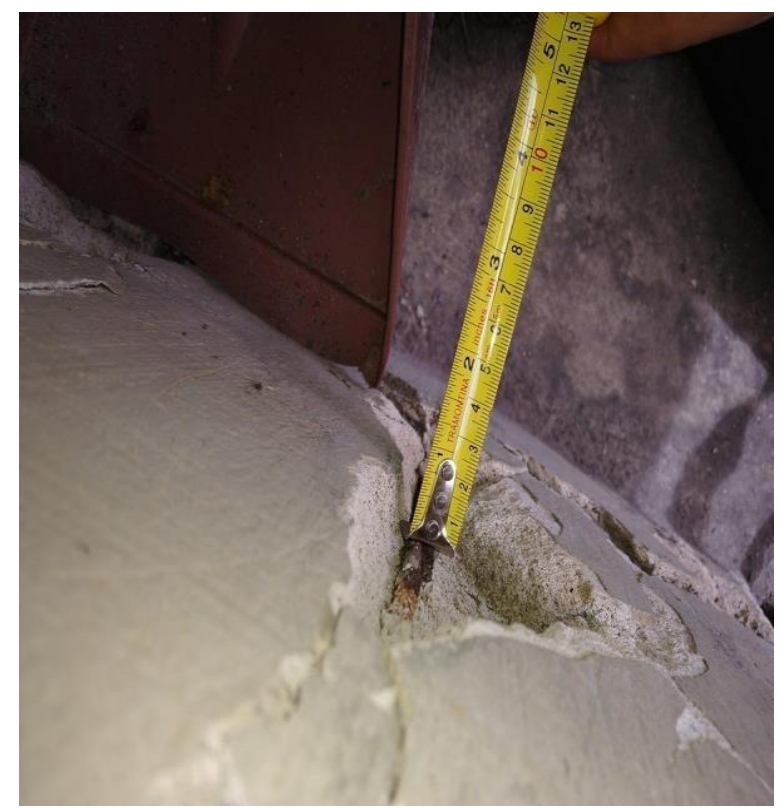

Figura 5 - Averiguação do cobrimento das brises

A situação de integridade das brises internas, com sua terminação no limite da alvenaria de vedação, estão em melhor estado que as externas a fachada. Partindo do pressuposto de que as brises foram feitas com materiais de mesmas características, seu nível de exposição a agentes agressivos impacta muito na formação de manifestações patológicas. Pelo que foi observado, é necessário um processo de restauração das brises menos agredidas e a substituição total das mais deterioradas.

\subsection{3 - Suportes para máquinas de climatização}

Os suportes metálicos das unidades condensadoras das máquinas de ar-condicionado, mostrado em detalhe na Figura 6, se encontram bastante deteriorados pela corrosão. Dessa maneira ficam bastante propensos a provocar um acidente, podendo cair em alguma pessoa ou veículo, já que na fachada leste, como mostra a Figura 7, ficam ao lado de um estacionamento.

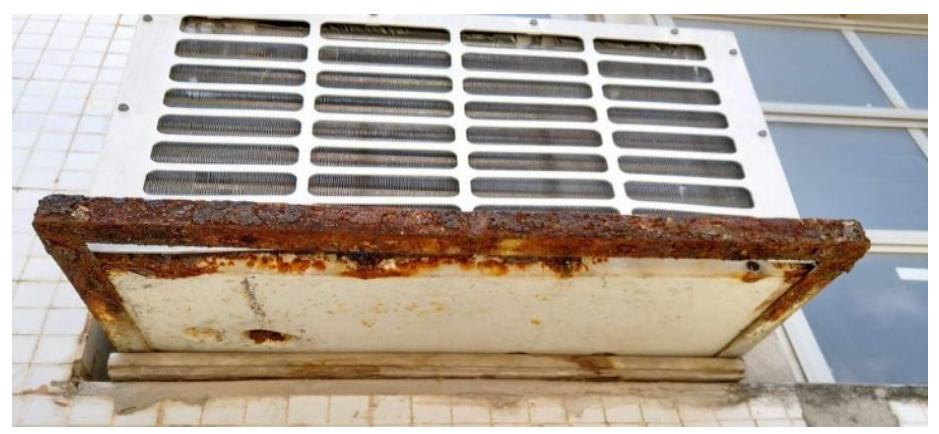

Figura 6 - Corrosão de um suporte de ar-condicionado 


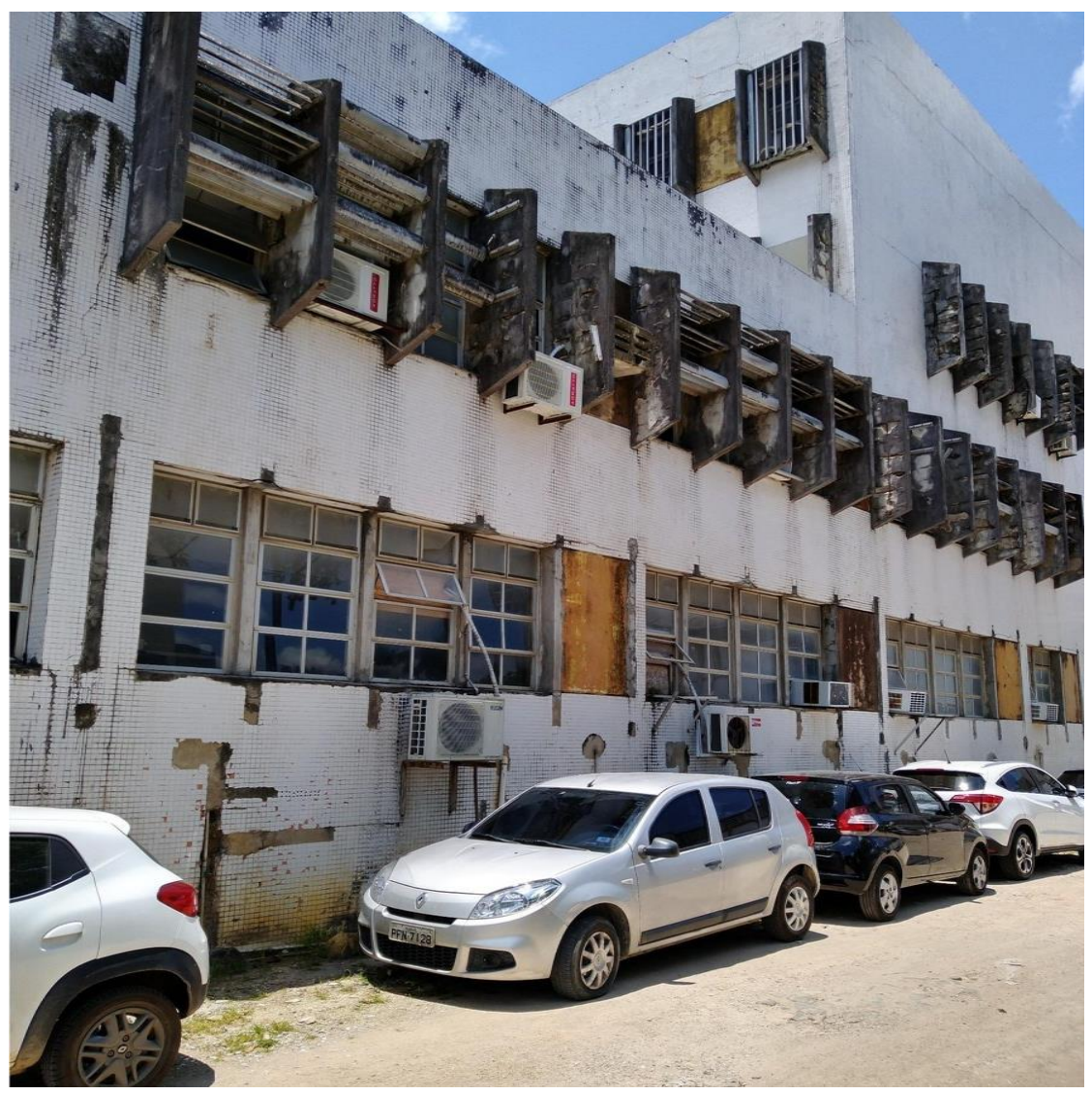

Figura 7 - Estacionamento da fachada leste

Este processo ocorreu ao longo do tempo, com a ação exclusiva de agentes da natureza, como sol, chuva e vento. Porém, é correto dizer que tal situação poderia ser evitada se houvesse uma rotina de manutenção, observando já de início o processo corrosivo e executando a substituição dos suportes.

\subsection{4 - Marquise}

$\mathrm{Na}$ inspeção das manifestações da pintura da marquise, um foco de corrosão foi identificado na armadura de junção entre a estrutura da marquise e a viga da fachada, apresentado na Figura 8.

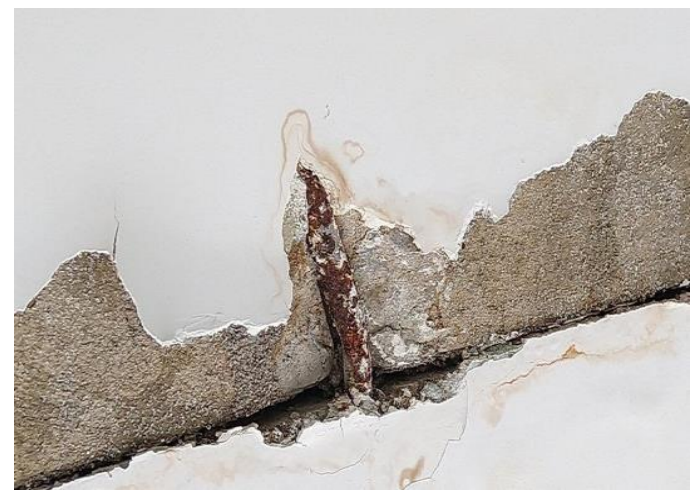

Figura 8 - Armadura da marquise corroída

Essa manifestação foi possível identificar por estar exposta, sem o cobrimento do concreto, porém é bem provável que existam demais trechos dessa junta com o mesmo problema, visto que as manchas de infiltração, apresentadas na Figura 9, se prolongam por todo o comprimento da marquise. Existem ensaios para analisar o processo de corrosão sem que haja a perturbação causada pela quebra de pedaços da marquise

para visualização armadura. 


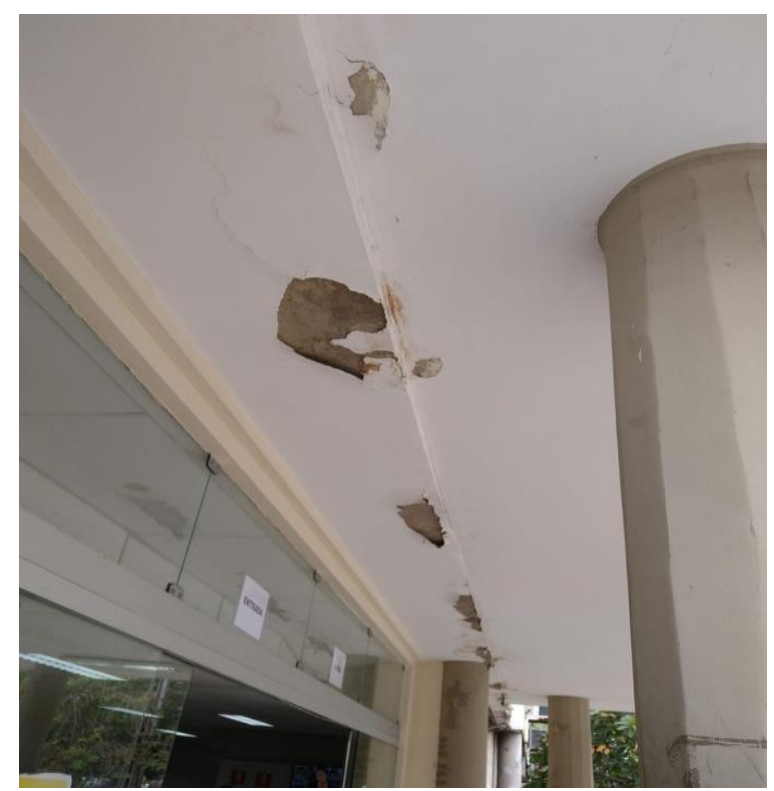

Figura 9 - Infiltração na junção entre a marquise e a fachada

\subsection{5 - Vergas de janela}

Na Figura 10 estão identificadas duas janelas da fachada oeste com as armaduras das vergas totalmente expostas, corroídas e sem parte do cobrimento de concreto. Como solução do problema é necessário fazer a recuperação da peça de concreto.

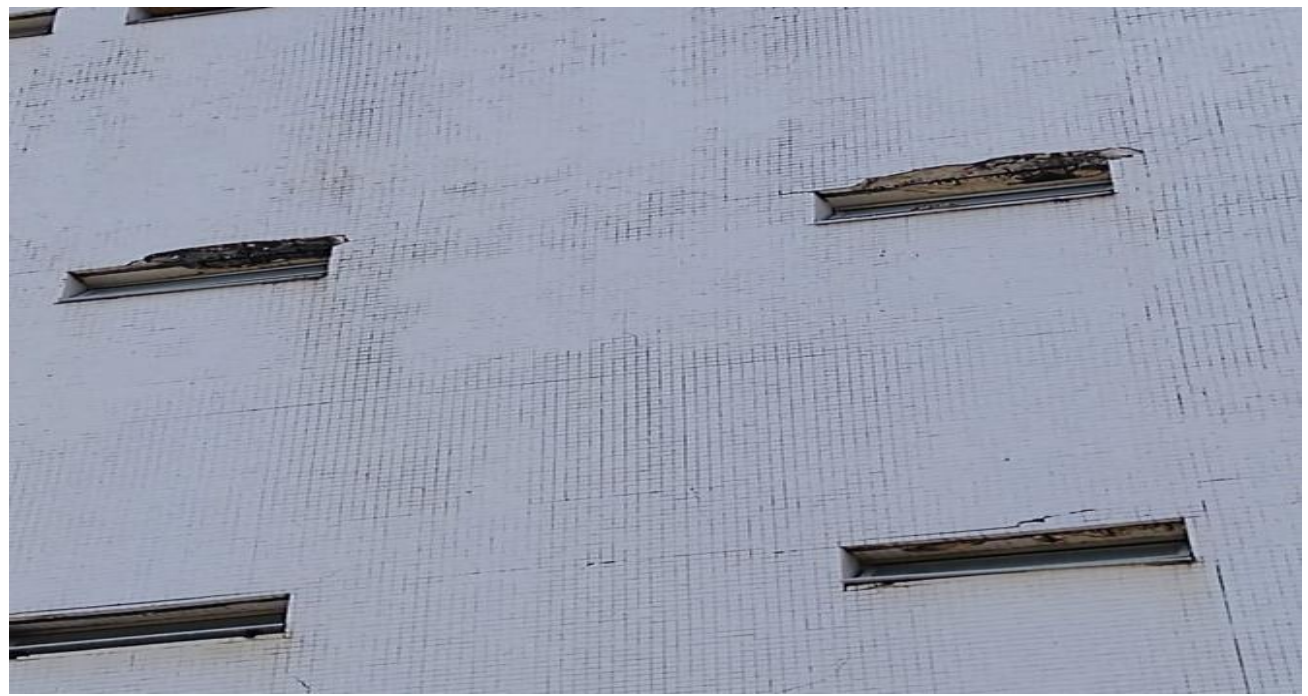

Figura 10 - Degradação nas vergas da fachada oeste

\subsection{Textura e pintura}

Foram identificados no prédio manifestações em dois tipos de pintura, pintura em tinta PVA e textura de arenito. $\mathrm{O}$ arenito é um tipo de textura feita com grãos de minerais, como o microsseixo. Estão presentes no revestimento de pintura manifestações como fissuras e descascamento, e outros 4 tipos muito similares, bolor, lodo, manchas e mofo. As origens das anomalias foram identificadas tanto como funcionais, tanto como endógenas. Destacando as endógenas temos o descascamento e fissuramento das pinturas do teto da marquise (tinta PVA), e da textura de arenito nos pilares. Em comparação à correção dos problemas no concreto e nas peças metálicas, a pintura é mais simples de resolver, sendo necessária a remoção e limpeza da pintura antiga, e a aplicação correta de um novo revestimento.

\subsection{1 - Textura de arenito.}

Esse tipo de textura é composta por uma resina que tem função de aglomerar e aderir os grãos de minerais à superfície. Esse tipo de pintura está presente nas fachadas das entradas do bloco ambulatorial (fachada 
norte) e na entrada da maternidade (fachada oeste), e também nos pilares da marquise. Sobre o descascamento nos pilares, foi observada a pouca aderência da textura ao substrato por falta de aplicação de selador, pois a mesma não apresentava resistência alguma ao processo de remoção. Outro fator que contribuiu para o aparecimento dessa manifestação foi a exposição à água, visto que a além da textura da parede da fachada ter descascado, somente o lado do pilar mais exposto à chuva foi danificado. Como pode ser observado na Figura 11, os pilares da marquise receberam em algum momento uma pintura por cima da textura, o que não impediu a entrada da água. Na Figura 12 também pode se identificar a falta de aderência dos grãos da textura e o seu descascamento.

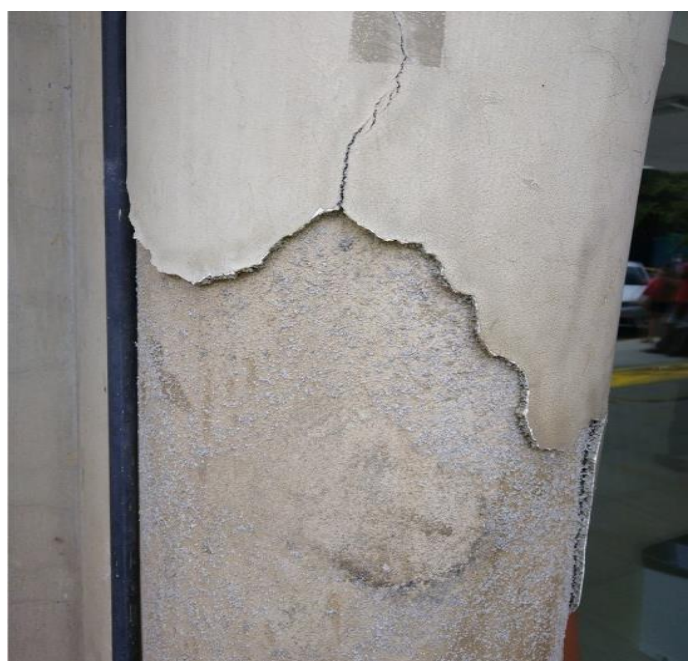

Figura 11 - Pintura sobre a textura

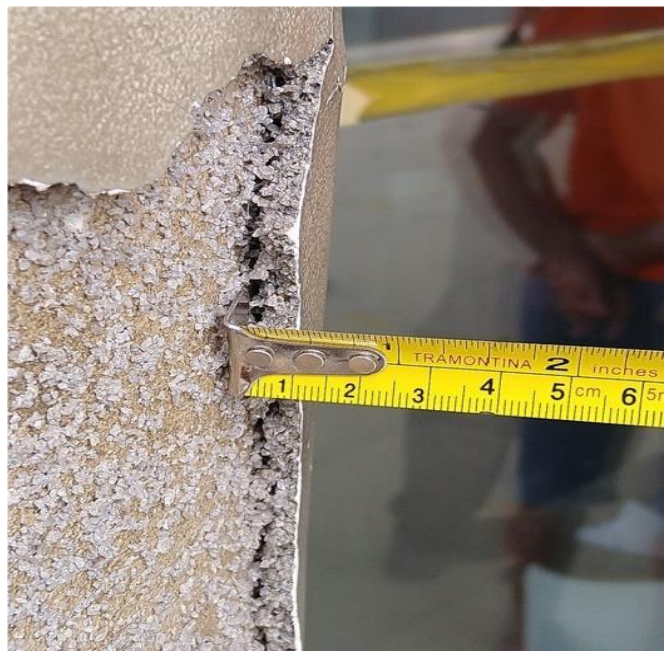

Figura 12 - Descascamento da textura

As paredes da fachada em arenito também apresentam a presença de lodo e bolor, tendo sua origem ligada a falta de limpeza da fachada. Na Figura 13 está um trecho da fachada principal com a presença dessas três manifestações.

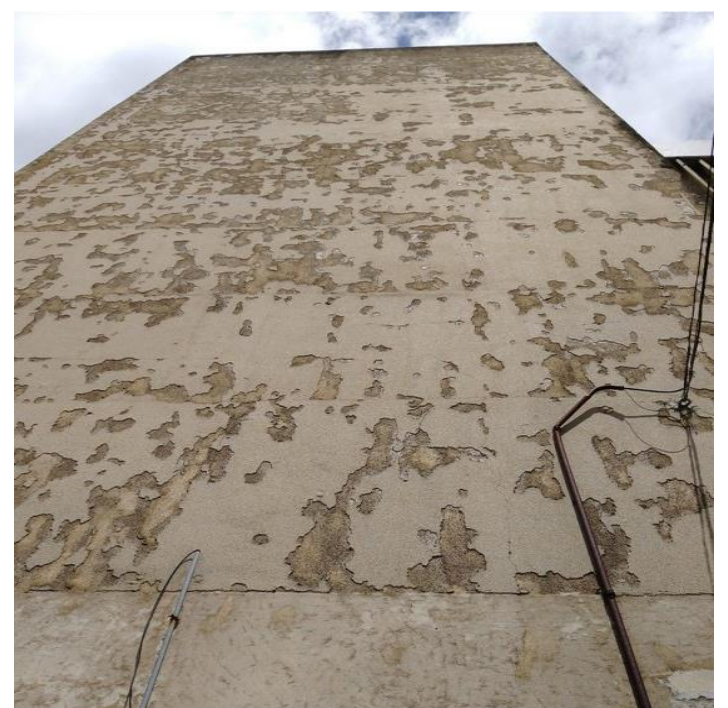

Figura 13: Algumas manifestações observadas na pintura da fachada

\subsection{2 - Pintura da marquise.}

O fundo da marquise pintado com tinta látex pva mostrado na Figura 12, apresenta muitos pontos próximos do seu bordo com descascamento provocado pelas infiltrações. Este processo é facilitado pela a ausência de pingadeira nos limites dos bordos, já que a água através de sua tensão superficial precipita 
próxima a estas localidades. Dessa forma ocorre o estufamento e enfraquecimento da pintura, resultando no seu descascamento além da formação das manchas de infiltração.

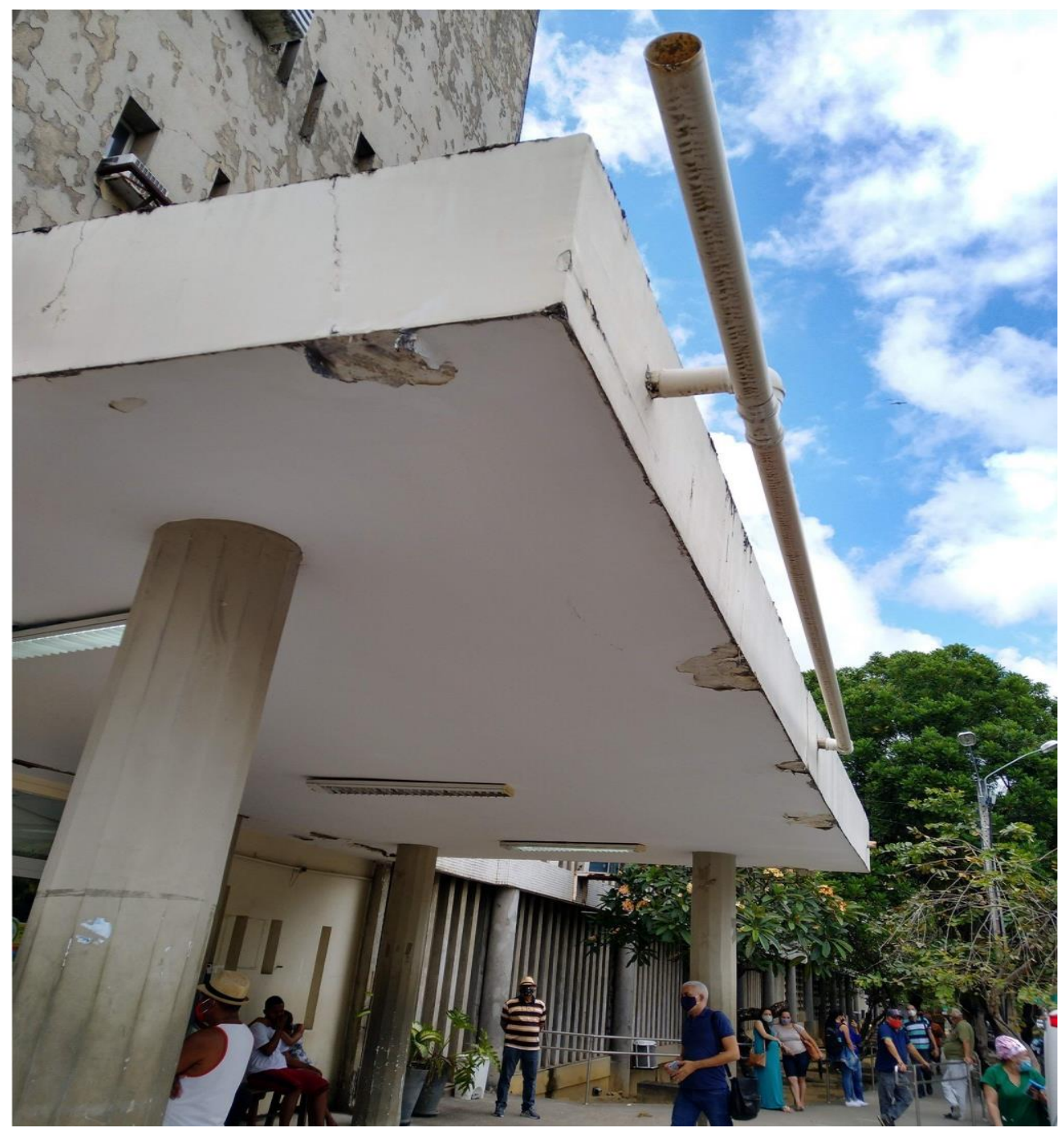

Figura 14 - Infiltração na marquise, ausência de pingadeira nas bordas

$\mathrm{Na}$ junção da marquise com a viga da fachada foi identificada a falta ou a falha de um serviço de impermeabilização, pois a água escorre exatamente nesse ponto, provocando também manchas de infiltração e o descascamento da pintura.

\subsection{Revestimento cerâmico.}

O revestimento cerâmico é predominantemente encontrado nas fachadas leste e oeste do prédio, e em um pequeno trecho na fachada principal. Na fachada leste se encontram os mais variados tipos de manifestações patológicas, formação de lodo, bolor, descolamento de pastilhas, gretamento e fissuras, na fachada oeste as mesmas manifestações foram observadas, porém em menor escala e na fachada principal só foi observável a sujeira. Além disso foi identificada a presença serviços mal executados e com falta de manutenção. No Quadro 3 estão expostas estes problemas e suas localidades além de regiões que sofreram danos pelos serviços mal executados. 
Quadro 3 - Problemas no revestimento cerâmico e suas localidades.

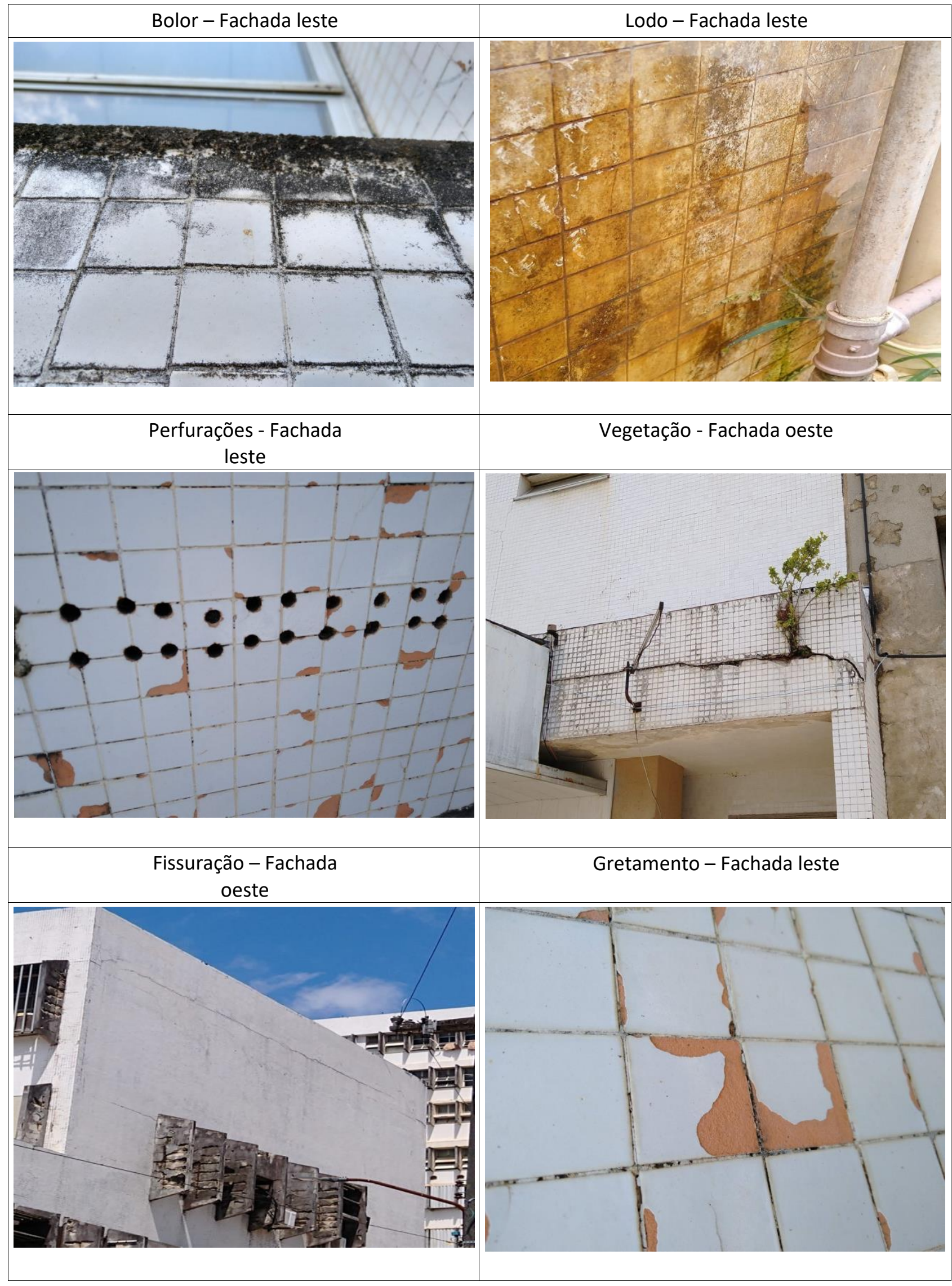


Com o seu traçado uniforme ao longo de onde se tem peças estruturais como vigas e pilares, as fissuras provavelmente foram causadas pelas tensões do encontro da alvenaria com a estrutura, solicitações a quais a cerâmica não suporta. Dois desses problemas apresentados foram causados por terceiros, vindos de serviços de adequação de infraestrutura. O vazamento que formou o lodo na fachada veio de uma instalação de água posterior à construção, podendo ter sua origem tanto na má execução da canalização ou por dano acidental. O excesso de perfurações para suportes metálicos torna-se porta entrada para a entrada de água, sujeira e outras substâncias, exemplificado pelo aparecimento de vegetação numa das fissuras. 0 gretamento e o bolor são originados naturalmente, uma vez que o revestimento por ser antigo, sofreu bastante as intempéries do meio.

Pode-se afirmar que a recuperação da fachada se torna mais complexa tamanha é a quantidade de problemas identificados. Dessa maneira o mais correto a se fazer seria a completa substituição do revestimento cerâmico e a recuperação das fissuras, lembrando de ser realizar manutenções principalmente a limpeza.

\section{Proposta de intervenção}

No Quadro 4 foram compiladas as informações sobre alguns dos elementos acometidos por manifestações patológicas, sinalizando para o seu tipo, sua possível causa e alternativa para correção do problema.

Quadro 4 - Caracterização das principais manifestações identificadas (continua).

\begin{tabular}{|c|c|c|c|c|}
\hline $\begin{array}{l}\text { Elementos da } \\
\text { fachada }\end{array}$ & Manifestações & Possíveis causas & Tipo & Correção \\
\hline Brises & $\begin{array}{l}\text { Corrosão e desplacamento } \\
\text { do concreto }\end{array}$ & $\begin{array}{l}\text { Causados pela } \\
\text { agressividade do meio }\end{array}$ & Funcional & $\begin{array}{l}\text { Tratamento da } \\
\text { corrosão e } \\
\text { recomposição do } \\
\text { concreto danificado }\end{array}$ \\
\hline Coberta metálica & Corrosão & $\begin{array}{l}\text { Causada pela } \\
\text { agressividade do meio }\end{array}$ & Funcional & $\begin{array}{l}\text { Substituição dos } \\
\text { trechos mais } \\
\text { corroídos e limpeza } \\
\text { e pintura dos } \\
\text { demais }\end{array}$ \\
\hline Suportes metálicos & Corrosão & $\begin{array}{l}\text { Causada pela } \\
\text { agressividade do meio }\end{array}$ & Funcional & Substituição total \\
\hline $\begin{array}{l}\text { Marquise } \\
\text { (armadura) }\end{array}$ & Corrosão & $\begin{array}{l}\text { Falta/falha de } \\
\text { impermeabilização }\end{array}$ & Construtiva & Exige ensaios \\
\hline Marquise (pintura) & $\begin{array}{l}\text { Estufamento, manchas e } \\
\text { descascamento }\end{array}$ & Ausência de pingadeira & Construtiva & $\begin{array}{l}\text { Execução de } \\
\text { pingadeiras e } \\
\text { impermeabilização }\end{array}$ \\
\hline Pilares com textura & Descascamento de pintura & $\begin{array}{l}\text { Falha de execução } \\
\text { (selador) }\end{array}$ & Exógena e Funcional & $\begin{array}{l}\text { Remoção do } \\
\text { revestimento antigo } \\
\text { e correta aplicação } \\
\text { da nova textura }\end{array}$ \\
\hline $\begin{array}{l}\text { Revestimento } \\
\text { cerâmico }\end{array}$ & $\begin{array}{l}\text { Presença de bolor, } \\
\text { vegetação, fissuras, etc }\end{array}$ & $\begin{array}{l}\text { Vida útil chegando ao } \\
\text { fim, falta de } \\
\text { manutenção e má } \\
\text { execução de serviços }\end{array}$ & Exógena e Funcional & $\begin{array}{l}\text { Remoção do } \\
\text { revestimento atual } \\
\text { e execução de novo } \\
\text { revestimento } \\
\text { cerâmico }\end{array}$ \\
\hline $\begin{array}{l}\text { Revestimento de } \\
\text { pintura }\end{array}$ & Descascamento de pintura & $\begin{array}{l}\text { Agressividade do meio } \\
\text { mais falha executiva }\end{array}$ & Exógena e Funcional & $\begin{array}{l}\text { Remoção do } \\
\text { revestimento antigo } \\
\text { e correta aplicação } \\
\text { de pintura para } \\
\text { exterior }\end{array}$ \\
\hline
\end{tabular}




\section{Conclusões}

Pode-se afirmar que é algo natural o surgimento de manifestações patológicas em edificações, principalmente em elementos em contato direto com a agressividade do meio ambiente, como é o caso da fachada e de seus componentes. Pela inspeção visual da fachada do prédio foram identificados problemas dos mais variados tipos, funcionais, construtivos ou de projeto e causados por terceiros. Destacaram-se pela quantidade os que foram adquiridos de forma natural e gradativa ao longo do tempo, o que não muda o fato que os mesmos poderiam ter sido evitados, interrompendo o seu agravamento em idades iniciais através de serviços de manutenção. Para isso, é necessário que haja um plano de inspeção para minimizar em quantidade e qualidade os problemas que venham a surgir num prédio. Para saber a correta elaboração das inspeções, o gestor da edificação deve consultar um profissional da área para que se faça esse acompanhamento. O profissional irá buscar em normas e manuais a correta realização das inspeções. Por exemplo, as normas da NBR 16747 (ABNT, 2020) e a do IBAPE (2012) dão diretrizes as inspeções prediais. Equipamentos como elevadores, geradores, máquinas de sauna e bombas de poço tem sua periodicidade de manutenção indicada em manuais ou pelos fornecedores do equipamento. Não havendo uma constância das investigações da situação geral do edifício, o custo, o trabalho e o impacto para um serviço de recuperação e manutenção será muito maior, ainda mais sendo um prédio que oferece serviço de saúde. Tendo assim, que a recuperação desses problemas citados no trabalho terão que ser feito por profissionais e empresas bem capacitadas, mantendo o nível de perturbação ao mínimo e garantindo a qualidade do serviço.

No estudo não foi possível fazer análise visual de todos os elementos e trechos da fachada, considerando a incapacidade de se observar pontos mais distantes da fachada e o difícil acesso as suas instalações, principalmente com a pandemia do COVID-19.

\section{Referências}

Associação Brasileira de Normas Técnicas - ABNT. NBR 6118:1980 Projeto de estruturas de concreto: Procedimento, Rio de Janeiro.

NBR 6118:2014 Projeto de estruturas de concreto: Procedimento, Rio de Janeiro. NBR 16747:2020 Inspeção predial - Diretrizes, conceitos,terminologia e procedimento, Rio de

Janeiro.

Lima. A.C. et al. Manifestações patológicas em estruturas de concreto armado no Hospital do Câncer de PE. In Anais, 6 Conferência sobre patologia e reabilitação de edifícios, Rio de Janeiro. Recuperado a partir de http://www.nppg.org.br/patorreb/files/artigos/80535.pdf

Departamento Nacional de Infraestrutura de Transnportes - DNIT. Manual de recuperação de pontes $e$ viadutos rodoviários. 1.ed. Rio de Janeiro, 2010.

Dos Santos. T.C.S. (2010). Plano de ação voltado à manutenção de sistemas de pinturas em escolas públicas. Especialização de Construção de Obras na Universidade Federal do Paraná, Paraná, 2010.

Groff. C. (2011). Revestimentos em fachadas: análise das manifestações patológicas nos empreendimentos de construtora em Porto Alegre. Trabalho de conclusão de curso. Universidade Federal do Rio Grande do Sul, Rio Grande do Sul, 2011.

HC celebra 41 anos de existência com evento on-line no próximo dia 24. EBSERH, 14 de set. De 2020. Disponível em: <http://www2.ebserh.gov.br/web/hc-ufpe/noticias/-/asset_publisher/FipO9upE5FZw/ content/id/5680366/2020-09-hc-celebra-41-anos-de-existencia-com-evento-on-line-no-proximo-dia24>. Acesso em: 15 de se. de 2020.

Instituto Brasileiro de Avaliações e Perícias de Engenharia - IBAPE. (2012). Norma de inspeção predial nacional, São Paulo. 
Silveira. V.C. (2019). Avaliação do potencial de formação do mofo em edificações residenciais em Florianópolis. Dissertação submetida ao Programa de Pós-Graduação em Arquitetura e Urbanismo. Universidade Federal de Santa Catarina, Santa Catarina, 2019.

Souto. B.P., Bezerra. R.S., Santana. P.L., Monteiro. E.B. Manifestações patológicas durante a revitalização de uma fachada de 60 anos. In Anais, 1 Conferência Nacional de Patologia e Recuperação de Estruturas, Recife. Recuperado a partir de http://revistas.poli.br/index.php/CONPAR/article/view/678

Terra. R.C. (2001). Levantamento de manifestações patológicas em revestimentos de fachadas das edificações da cidade de Pelotas. Dissertação de mestrado em Engenharia Civil, Universidade Federal do Rio Grande do Sul, Rio Grande do Sul, 2001.

Oliveira. G. M. V., Caldeira, P. H. A., Silva Junior, L. A. \& Viera, A. C. (2019). Análise de fissuras em alvenaria de vedação - Estudo de caso. Universidade Estadual de Minas Gerais - Unidade de João Monlevade. Research, Society and Developmant, Minas Gerais, 2019. 